\title{
As implicações do uso do álcool gel na microbiota das mãos durante a pandemia
}

\section{The implications of alcohol gel use on hand microbiota during the pandemic}

\author{
Jenyffer Sylvia Saraiva Rosa ${ }^{1}$, Pedro Augusto Ramos Vanzele, ${ }^{2}$, Hadassa Christina de Azevedo \\ Soares dos Santos ${ }^{1}$
}

\begin{abstract}
RESUMO
A superfície epitelial da pele é colonizada por diversos microrganismos que coletivamente são chamados de microbioma. As bactérias presentes normalmente nesse ambiente são necessárias para aumentar a imunidade e resistência a infecção por outros microrganismos. Quando há um desequilíbrio nessa microbiota em questão, outros microrganismos, patogênicos ou não, podem se proliferar e ocasionar doenças. Inúmeros fatores podem ser elencados como contribuintes para gerar esse desequilíbrio e, um deles, seria o uso de agentes químicos durante a higienização. O presente estudo teve como objetivo avaliar alterações no microbioma das mãos decorrentes do uso frequente do álcool gel e verificar com outros estudos para saber se tem semelhança com profissionais da saúde. Como resultados mais importantes, a presença de Staphylococcus coagulase -, Staphylococcus aureus, Corynebacterium sp.,Micrococcus sp., Escherichia coli e Bastonetes Gram +, coincidindo com outras pesquisas de relevância. Com a pandemia de COVID-19, muito se discute sobre a utilização do álcool gel e, sendo ele um componente químico, é importante investigar os danos que pode trazer à microbiota natural da pele, porém o álcool é um componente químico e como tal, pode causar danos no futuro.
\end{abstract}

Palavras-chave: Microbioma; Álcool gel; Bactérias; Pandemia e Desequilíbrio.

\begin{abstract}
The epithelial surface of the skin is colonized by several microorganisms that collectively are called the microbiome. Bacteria normally present in this environment are necessary to increase immunity and resistance to infection by other microorganisms. When there is an imbalance in this microbiota in question, other microorganisms, pathogenic or not, can proliferate and cause disease. Numerous factors can be listed as contributors to this imbalance, and one of them would be the use of chemical agents during cleaning. The present study aimed to evaluate changes in the microbiome of the hands resulting from the frequent use of alcohol gel and to check with other studies to find out if it is similar to health professionals. As the most important results, the presence of Staphylococcus coagulase -, Staphylococcus aureus, Corynebacterium sp., Micrococcus sp., Escherichia coli and Rods Gram +, coinciding with other relevant researches. With the COVID-19 pandemic, there is much debate about the use of alcohol gel and, as it is a chemical component, it is important to investigate the damage it can bring to the skin's natural microbiota, but alcohol is a chemical component and as such, may cause damage in the future.
\end{abstract}

\footnotetext{
${ }^{1}$ Centro Universitário Sul de Minas, Grupo UNIS, Varginha, Minas Gerais, Brasil

${ }^{2}$ Departamento de Análises Clínicas e Toxicológicas, FCF-USP, São Paulo, São Paulo Brasil
} 
Keywords: Microbiome; Alcohol gel; Bacteria; Pandemic and Imbalance.

\section{INTRODUÇÃO}

No fim de 2019 em Wuhan (China), houve o primeiro caso da doença respiratória causada pelo SARS-CoV 2, que acabou ocasionando uma contaminação em massa, o número de óbitos alcançou proporções astronômicas, e com isso, a sociedade precisou reforçar os hábitos de higienização, principalmente para prevenir o contágio e transmissão da doença, esses meios foram amplamente divulgados e reforçados pelo Ministério da Saúde no ano de 2020. Uma destas formas de higienização recomendada por cientistas é a antissepsia das mãos com o uso de álcool gel. De acordo com Oliveira e Lemos (2021), existem diversas formas de álcool e em diferentes concentrações, porém, o mais recomendado pela OMS é o álcool gel 70\%, concentração esta que apresenta capacidade de inativar o vírus, segundo o Conselho Federal de Química (CFQ). O álcool gel é composto por álcool líquido 70\% (solução de álcool etílico em água), glicerina (que serve como umectante), carbopol (polímero acrílico formador de gel) e trietanolamina (substância neutra). Como todo produto químico, é necessário que ele passe por um controle de qualidade, como por exemplo, a verificação do pH, o qual tem de estar neutro para não causar irritação e alergias (CATHARIN, 2020).

Porém, um importante ponto a se considerar é que a pele dos indivíduos, inclusive nas mãos, serve como uma barreira natural para proteger o corpo de agressões, funcionando como uma primeira barreira imunológica, além de abrigar uma imensa variedade de espécies bacterianas (GRICE; SEGRE, 2011).

De acordo com Bernardo, Santos e Silva (2019), a pele é constituída essencialmente por três camadas: epiderme, derme e hipoderme. A epiderme (camada externa) é constituída por células epiteliais sobrepostas que quando são consideradas de dentro para fora estão dispostas em: basal, espinhosa, granulosa, lúcida e córnea (DOMANSKY; BORGES, 2012). A segunda camada é a derme, que é mais profunda e é composta por tecido conjuntivo denso irregular. É uma camada cutânea presente entre a epiderme e o tecido subcutâneo, ricamente constituído por elastina e fibras de colágeno. A terceira e última camada é chamada hipoderme, sendo considerada um órgão endócrino, constituído por adipócitos, tendo a função de reserva energética, assim como proteção contra choques térmicos e modelagem do corpo (OLIVEIRA, 2011; TASSINARY, 2019).

A camada mais superficial do sistema tegumentar ainda detém a função de servir como microrganismos colonizadores, os quais em conjunto compõem o que é conhecido por 
microbiota da pele (TWO et al., 2016). De acordo com Dreno et al., (2016), existem bactérias presentes nesse nicho e que convivem naturalmente em equilíbrio com seu hospedeiro e, quando há alterações neste equilíbrio, ocorre a chamada disbiose. Esse processo é caracterizado por um distúrbio na microbiota natural de um organismo, e pode levar a proliferação de novas bactérias, patogênicas ou não, propiciando o surgimento de determinadas doenças, como acne, impetigo (Staphylococcus aureus e Streptococcus pyogenes), foliculite bacteriana (Staphylococcus aureus), erisipela e celulite (Streptococcus beta-hemolíticos), furúnculo e abscesso (Staphylococcus sp.) (RODRIGUES, et al., 2010).

Segundo Schommer e Gallo (2013), a pele fornece muitos nichos nos quais grandes microrganismos são submetidos a pressões ecológicas variáveis, incluindo umidade, temperatura, $\mathrm{pH}$ e a composição de peptídeos e lipídeos antimicrobianos. São conhecidos pelo menos dezenove filos de bactérias que fazem parte do microbioma da pele, e os principais exemplos são Actinobacteria, Firmicutes, Proteobacteria e Bacteroidetes. Grande parte dos gêneros identificados são Corynebacterium, Propionibacterium e Staphylococcus. Cada grupo depende das características fisiológicas do nicho apropriado. Nos lugares mais sebáceos, como o rosto, são predominantes espécies de Corynebacterium e Staphylococcus. Em locais mais úmidos, como a axila, espécies de Corynebacterium são predominantes. Em locais secos, populações mistas de espécies bacterianas de $\beta$-Proteobacteria e Flavobacteriales fazem parte da microbiota residente. Ainda, foi comprovado que o epitélio é bem mais do que um simples hospedeiro passivo de microrganismos, mas também requer a contribuição de bactérias residentes para aumentar a imunidade e resistência à infecção por microrganismos patogênicos não residentes (SANFORD, GALLO, 2013).

Normalmente, a microbiota das mãos possui bactérias transitórias e residentes (DRÉNO et al., 2016). As bactérias transitórias colonizam a camada superior da pele e podem ser removidas com a lavagem correta das mãos. Algumas bactérias transitórias podem ser patogênicas e causar infecções oportunistas. As bactérias residentes estão em uma camada mais profunda e são difíceis de serem removidas (GAUER; SILVIA, 2016).

Dadas tais informações, o ponto principal dessa pesquisa é avaliar a composição da microbiota das mãos de indivíduos em diversas áreas de atuação durante a pandemia e o uso recorrente de álcool gel, verificando assim se existem semelhanças com o encontrado em profissionais de saúde, que já fazem o uso recorrente deste produto. Ressalta-se que esse projeto não tem o intuito de levar a população a repensar o uso do álcool nesse período onde o mesmo é tão importante, mas para que a sociedade possa ter conhecimento caso o álcool em gel seja capaz de causar alterações significativas na composição da microbiota das mãos. 


\section{MATERIAIS E MÉTODOS}

Este projeto foi realizado através de uma pesquisa de campo, de caráter transversal, feita com profissionais do Grupo UNIS. O projeto foi enviado com antecedência e aprovado pelo Comitê de Ética em Pesquisa (CEP), sob CAAE 44553521.6.0000.5111 antes de iniciar as coletas. A parte de pesquisa de artigos foi feita pelas plataformas Google Acadêmico e PubMed, com as palavras Hand Microbiota, Microbiota das mãos, Microbiota das mãos em profissionais da saúde, sendo os artigos pesquisados em inglês e em português.

Antes de iniciar a coleta, foi necessário fazer os meios de cultura, e para isso, foi utilizado os ágares BHI, MANITOL e MACCONKEY. As proporções e medidas utilizadas estão especificadas no quadro 1.

Quadro 1 - Proporções e medidas de ágar utilizados.

\begin{tabular}{|l|l|l|}
\multicolumn{1}{c}{ Ágar } & \multicolumn{1}{c}{ Água Destilada } & $37 \mathrm{~g}$ \\
\hline BHI & 1 LITRO & $75,15 \mathrm{~g}$ \\
\hline Manitol & $650 \mathrm{ml}$ & $26 \mathrm{~g}$ \\
\hline MacConkey & $650 \mathrm{ml}$ & Qúgar \\
\hline
\end{tabular}

Fonte: Próprio autor

Após a mistura de ágar e água estarem feitas e devidamente homogêneas, foi necessário colocá-los na autoclave, no máximo de aquecimento, até chegar no $121^{\circ} \mathrm{C}$. Após isso, a autoclave foi colocada na temperatura média por mais 15 minutos até desligar. Depois que os ágares foram retirados da autoclave, aguardou-se um tempo até que parasse de borbulhar para poder transferir para as placas de Petri. O BHI foi colocado na placa grande de 90X15MM e os ágares Manitol e MacConkey 49 x 12 MM.

A coleta teve início no dia 22 de junho de 2021, feita mediante o uso de swabs embebidos em soro fisiológico estéril, passando em toda a região palmar e espaço interdigital das mãos de 8 homens e 7 mulheres adultos, os quais permaneceram em atividade durante o período da pandemia. Após a coleta, o swab foi colocado em um meio Stuart de transporte para que não haja contaminação até que seja feito o esfregaço na placa com ágar.

Os swabs de cada um dos pacientes foram semeados diretamente em uma respectiva placa de ágar BHI, e incubados em estufa por 24 horas à $37^{\circ} \mathrm{C}$, juntamente com os meios Stuart de transporte. Os voluntários foram identificados por letras de A até O, e cada colônia diferente era identificada e isolada em uma nova placa de ágar BHI e, novamente, levada para a estufa 
por mais 24 horas à $37^{\circ} \mathrm{C}$. Com o crescimento nessa nova placa e com as colônias devidamente separadas, utilizou-se das placas de Manitol e MacConkey para novos testes de identificação.

Após estes processos, foi realizada a técnica de coloração de Gram para saber quais colônias eram Gram positivas e quais eram Gram negativas. Na microscopia, as colônias foram observadas na objetiva de imersão. Após serem classificadas de acordo com sua coloração, bactérias Gram negativas foram semeadas em meio Rugai com Lisina, para visualização de parâmetros bioquímicos que auxiliariam na identificação dos microrganismos.

Outro teste bioquímico realizado foi o teste de catalase em lâminas de vidro, utilizando água oxigenada volume 10. As colônias bacterianas foram manipuladas com hastes de madeira para que não houvesse riscos de resultados falso-positivo. Após todos esses testes, a identificação ficou mais clara e precisa de ser feita e os resultados serão abordados no próximo tópico.

\section{RESULTADOS}

No presente estudo, o principal objetivo foi verificar se houve alteração na microbiota das mãos de pessoas que continuaram trabalhando durante a pandemia e relacionar com outros estudos que falam sobre profissionais da saúde para saber se teve alguma semelhança. A amostragem foi de 15 pessoas, entre homens e mulheres, trabalhadores do Grupo Unis, de uma faixa etária de 21 até 55 anos, que continuaram trabalhando no período da pandemia. A partir deste grupo, um total de 25 bactérias foram identificadas, sendo Staphylococcus coagulasenegativa (56\%), Staphylococcus aureus (20\%), Bastonetes Gram-positivos (8\%), Escherichia coli (8\%), Corynebacterium sp. (4\%) e Micrococcus sp. (4\%), sendo eles representados na Figura 1. 
Figura 1 - Total de bactérias isoladas.

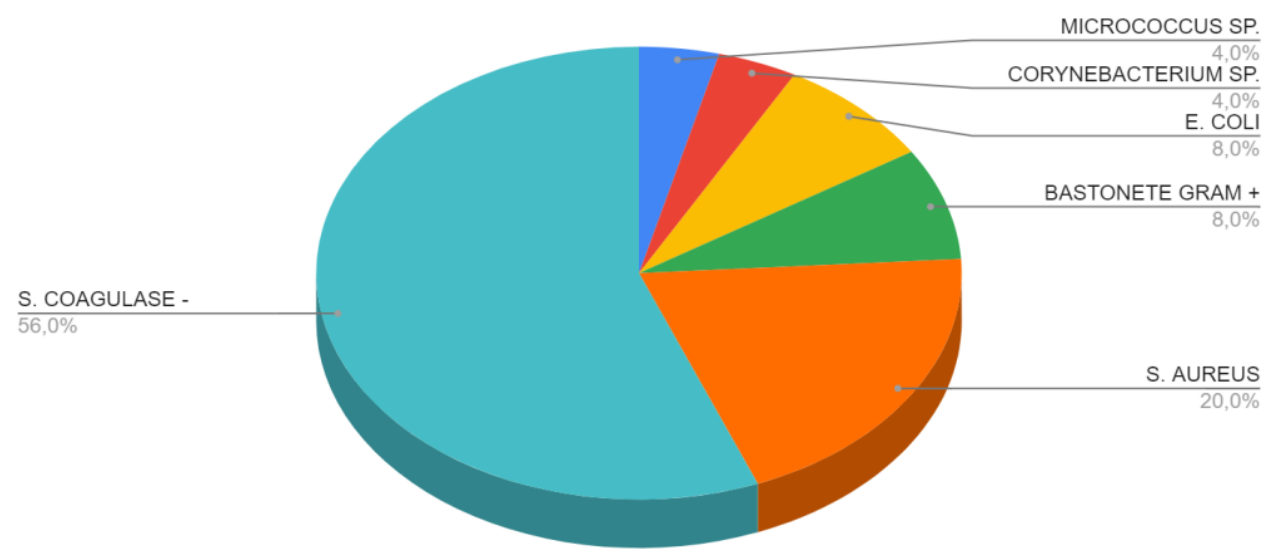

Fonte: Próprio autor

Os filos encontrados na presente pesquisa foram Actineobactéria (16\%), Proteobactéria $(8 \%)$ e Firmicutes (76\%). Esses dados estão inseridos na Figura 2.

Figura 2 - Filos encontrados.

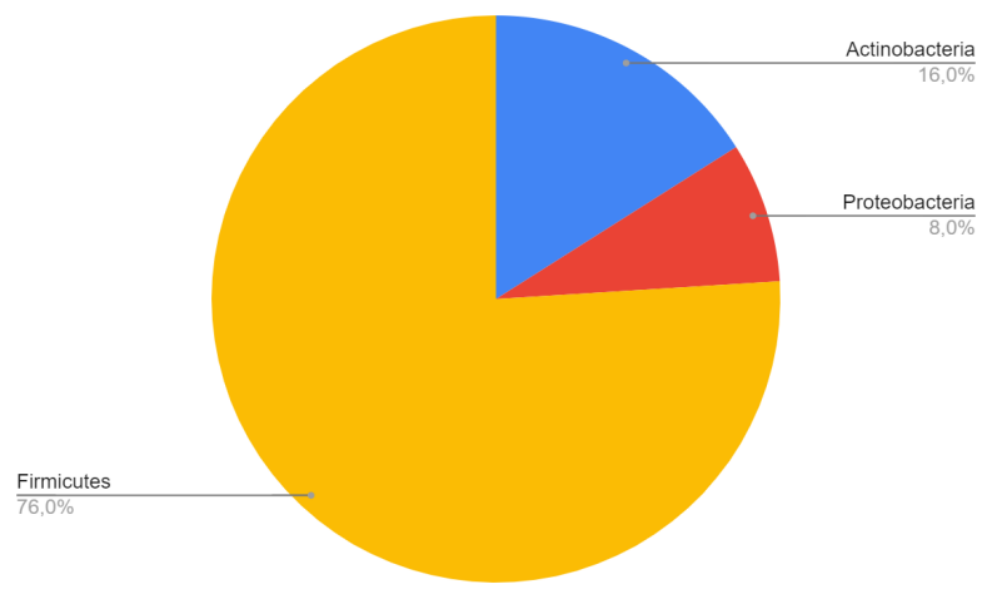

Fonte: Próprio autor

Essa pesquisa foi feita a partir de métodos qualitativos, que mesmo sendo de grande importância para este projeto, ainda seria necessário métodos de biologia molecular para os resultados serem mais fidedignos.

\section{DISCUSSÃO}

A superfície epitelial da pele é colonizada por diversos microrganismos que coletivamente são chamados de microbioma (TWO et al., 2016). Foi comprovado que o epitélio 
é bem mais do que um simples hospedeiro passivo de microrganismos, mas também requer a contribuição de bactérias residentes para aumentar a imunidade e resistência a infecção por microrganismos patogênicos não residentes (SANFORD; GALLO, 2013). A colonização da pele começa no início da vida neonatal e é importante para estabelecer uma tolerância imunológica contra microrganismos comensais. A microbiota muda constantemente no decorrer da vida, porém, na idade adulta, apesar da exposição contínua da pele ao meio ambiente, a composição permanece estável durante este período, sugerindo que existem interações benéficas entre os microrganismos comensais e o hospedeiro (CHEN; FISCHEBACH; BELKAID, 2018).

De acordo com a Figura 1, a bactéria mais encontrada foi Staphylococcus aureus e Staphylococcos coagulase -. Esses tipos específicos de bactérias são consideradas comensais, ou seja, fazem parte da microbiota normal da pele, regulam a homeostase desse microbioma e ainda podem auxiliar no combate de patógenos (SIVIERI et al., 2021). Segundo o artigo de Queiroz (2017), a produção de linfócitos T reguladores FoxP3 é proveniente de uma interação entre o Staphylococcus epidermidis e as células de Langerhans. Não é certo, porém cogita-se que esses microrganismos são importantes para a redução da resposta inflamatória grave proveniente de uma resposta imunológica contra outros tipos de bactérias comensais.

Os microrganismos mais encontrados na microbiota residente são os Staphylococcus coagulase negativo e algumas espécies de Corynebacterium. Já na microbiota transitória são encontradas mais bactérias Gram-negativas, como Enterobactérias, Pseudomonas, bactérias formadoras de esporos, fungos e vírus com maior potencial patogênico (SANTOS, 2009). Isso comprova que os estudos realizados neste projeto vão de acordo com outros estudos. A figura 3 mostra a diversidade encontrada no microbioma da pele, inclusive nas mãos. 
Figura 3- Distribuição topográfica de bactérias de diversos locais da pele.

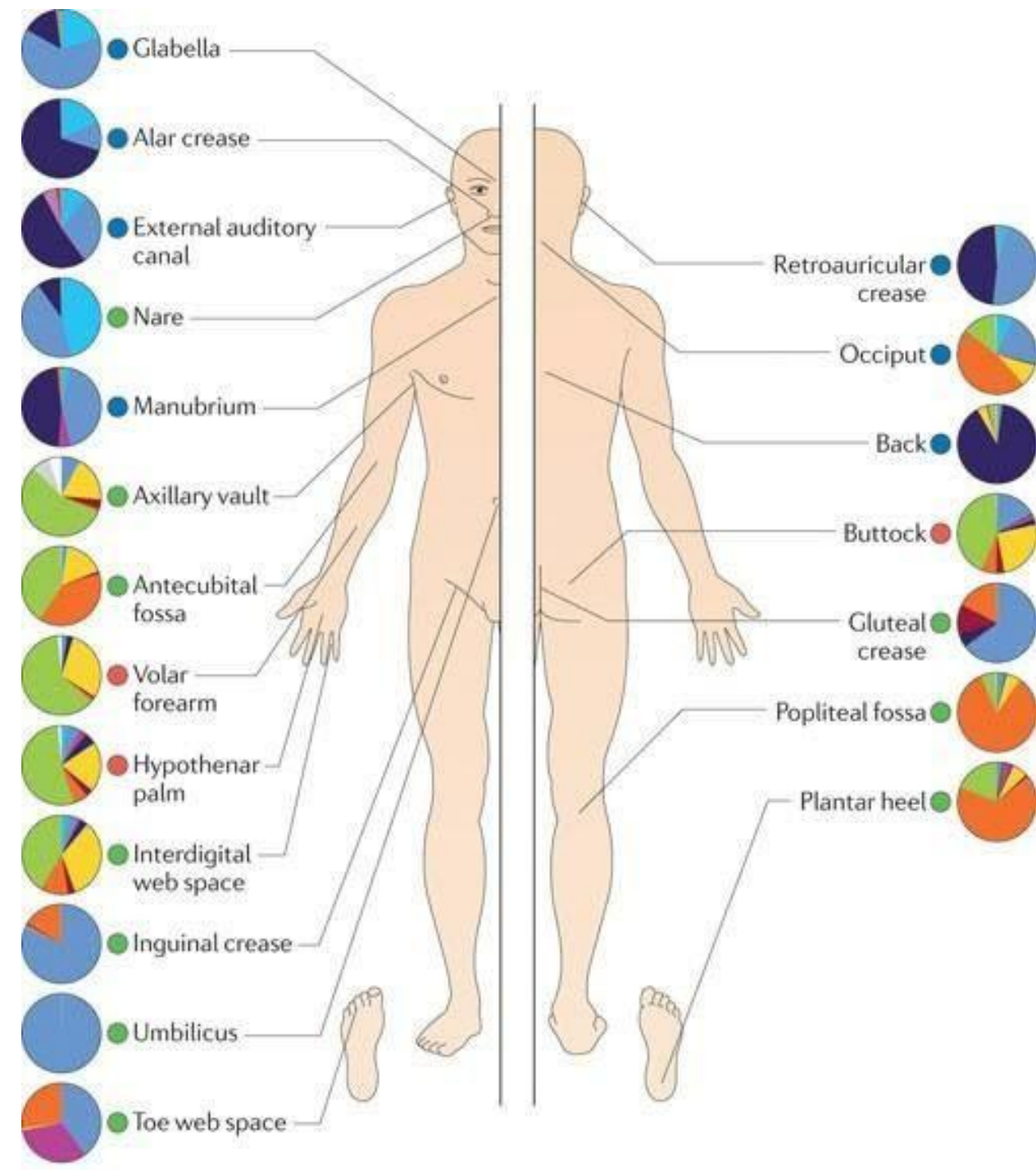

\begin{tabular}{|lll|}
\hline Actinobacteria & $\square$ Bacteroidetes & $\square$ Proteobacteria \\
$\begin{array}{ll}\text { Corynebacteriaceae } \\
\text { Propionibacteriaceae }\end{array}$ & Cyanobacteria & $\square$ Divisions contributing < 1\% \\
Micrococciaceae & Firmicutes & $\square$ Unclassified \\
Other Actinobacteria & Other Firmicutes & Sebaceous \\
& Staphylococcaceae & Moist \\
& & D Dry \\
\hline
\end{tabular}

Fonte: Grice; Segre (2011).

No artigo de Queiroz (2017), é citado que existem mais de 25 filos diferentes na microbiota da pele e, que os que estão em maior quantidade são Actineobactéria, Firmicutes e Proteobacteria, que vai de acordo com os testes realizados no presente artigo e que foram indicados na Figura 2. 
Para Wilson e colaboradores (2015), as mãos servem como um canal de troca de microrganismos entre o meio ambiente e o corpo, podendo abrigar espécies potencialmente patogênicas, incluindo Staphylococcus aureus e Escherichia coli. Um ponto interessante é que esse ambiente além de poder transportar patógenos, são ao mesmo tempo fonte de bactérias benéficas que contribuem para o bem estar do microbioma saudável do homem.

Grice e Segre (2013) entendem a pele como um ecossistema, o qual é composto por componentes físicos e biológicos que vivem em equilíbrio com o hospedeiro. Quando ocorre algum tipo de desequilíbrio, conhecido como disbiose, o resultado é o surgimento de infecções e doenças na pele, que pode se dar devido a fatores endógenos ou exógenos. A pele é colocada em prova sempre, pois seu habitat é diariamente desafiado, um exemplo disso seria a lavagem frequente das mãos e o uso de álcool em gel.

Para Dreno et al (2016), a lavagem frequente perturba a barreira da pele, resultando em sua irritação e alterações no microbioma da pele das mãos. Produtos químicos, como cosméticos, cremes, maquiagens e produtos de higiene estão ligados na modificação da microbiota local. De acordo com Kampf e Kramer (2004), cada vez que se lava as mãos alterase a camada de água-lipídio da pele superficial, ocasionando na perda de vários agentes protetores, como aminoácidos e fatores de proteção antimicrobianos. A perda de água transepidérmica aumenta e como consequência a pele se torna mais permeável aos agentes tóxicos e, ao mesmo tempo, as células superficiais da pele ressecam, o que resulta em deficiência do estrato córneo. A higienização com álcool faz com que a pele permaneça intacta, a hidratação dérmica não muda bruscamente e o conteúdo de sebo dérmico permanece inalterado, no entanto, a exposição repetida ao álcool pode causar ou manter a secura da pele. Ainda, sabe-se que o álcool é um antimicrobiano eficaz contra vários agentes (bactérias, fungos e vírus).

O artigo de Gonçalves et al. (2021), cita que durante a pandemia é importante a higienização das mãos com água, sabão e álcool gel, pois o mesmo se mostra eficaz no combate ao vírus. Em trabalhadores da área da saúde, foram feitos estudos que comprovam que a utilização de álcool reduz o número de microrganismos nas mãos desses profissionais, reduzindo assim, as taxas de infecções nosocomiais. Para provar essa hipótese, uma pesquisa realizada antes e após a higienização das mãos com água, sabão e álcool gel 70\%, reduziu o número de unidades formadoras de colônias (BATISTA et al. 2021).

Gauer e Silva (2016), fizeram um estudo muito semelhante com o da presente pesquisa, o qual também utilizou de métodos de cultura para a identificação dos microrganismos, com base no crescimento bacteriano. Apesar dos autores utilizarem Ágar Sangue ao invés de Ágar 
BHI, como neste estudo, os resultados foram bem compatíveis. A amostragem deles foram profissionais de um posto de saúde e os utensílios utilizados por eles, e os principais microrganismos identificados foram Staphylococcus aureus (44\%), Staphylococcus sp. (33\%), Escherichia coli (15\%), Pseudomonas aeruginosa (4\%), Enterobacter aerogenes (2\%) e Shigella sp. $(2 \%)$..

Figura 4- Total de microrganismos identificados isolados nas mão e utensílios

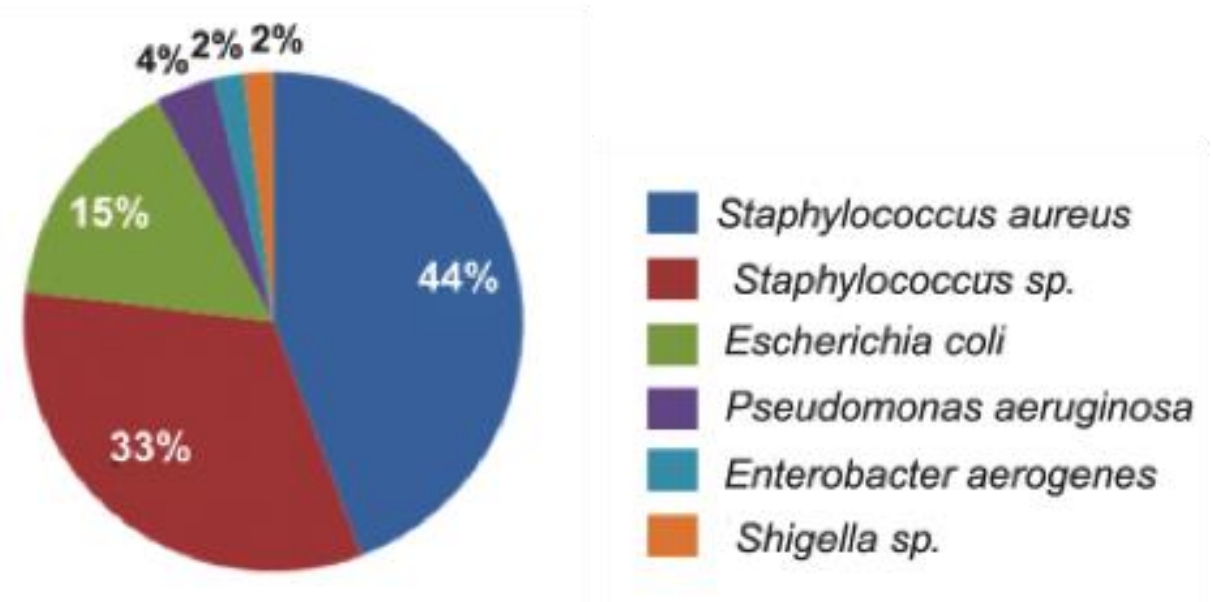

Fonte: Gauer e Silva, 2016.

Corroborando com os resultados dessa pesquisa, o artigo de Rocha (2007), de metodologia semelhante, entretanto com técnicas um pouco mais específicas para identificação das bactérias, além de terem coletado amostras antes e após lavagem das mãos dos profissionais da saúde, evidenciou a presença dos microrganismos $S$. aureus, S. coagulase-negativa, Enterobacter spp. e Serratia sp. O gênero Staphylococcus também foi encontrado em maiores proporções no presente estudo.

O artigo de Nogueira et al. (2021), citam que a higienização das mãos com água e sabão se mostra eficiente e reduz o número de microrganismos transitórios e resistentes, impedindo a disseminação de várias doenças. O uso de álcool gel 70\% tem um potencial de higienização maior, porém ainda não deve ser substituído pela lavagem antecipada. No estudo de ShimoyaBittencourt et al. (2019), afirmam que a utilização de álcool gel 70\% associado a lavagem das mãos tem um efeito benéfico e os efeitos microbiológicos são potencializados. Estudos apontam que o álcool pode causar efeito cumulativo por uso e com isso, reduz as taxas de infecção principalmente em ambientes hospitalares. 


\section{CONCLUSÃO}

Com a pandemia da COVID-19, mudanças de hábito foram necessárias para podermos controlar a disseminação do vírus enquanto a vacina não estava pronta. A OMS recomendou o distanciamento social, o uso de máscaras e principalmente a higienização das mãos com água, sabão e álcool gel 70\%. No decorrer dessa pesquisa, observamos que a microbiota das mãos de profissionais da saúde carregam diversos tipos de bactérias que são normalmente encontradas na pele e outras que são patogênicas. A importância de se lavar corretamente as mãos é para não ocorrer contaminação de um paciente para outro. Com as pesquisas feitas no laboratório, observamos que a microbiota dos voluntários não teve alteração significativa, que foram encontrados os mesmos microrganismos de outras pesquisas relacionadas com o assunto. Outro ponto importante é que qualquer tipo de produtos químicos pode causar problemas na pele, inclusive o álcool gel, porém acaba por ser a melhor opção restante durante esse período. $\mathrm{O}$ álcool, por matar vários tipos de bactérias, não faz uma seleção de quais microrganismos são bons ou ruins. O corpo humano é composto de bactérias que são necessárias para a nossa proteção e o uso de álcool gel reduz microrganismos descritos como transitórios, sem gerar grandes impactos na proteção da pele. É importante realizar outros estudos após a pandemia para averiguar se esse componente foi prejudicial à microbiota da pele.

\section{REFERÊNCIAS}

<https://pesquisa.bvsalud.org/portal/resource/pt/lis-23083 > Acesso em 19 de Outubro de 2020.

<https://www.cosmeticsonline.com.br/ct/painel/class/artigos/uploads/9eb2aCT304_Integra.pdf> Acesso em 19 de Outubro de 2020.

BATISTA, É. S. et al. Efficacy of hand hygiene products: A quasi-experimental study / Eficácia de produtos de higienização das mãos: estudo quase-experimental. Revista de Enfermagem da UFPI, v. 10, n. 1, 2021.

BERNARDO, A.; SANTOS, K.; SILVA, D. Pele: alterações anatômicas e fisiológicas do nascimento à maturidade. Revista Saúde em Foco., v. 19, n. 11, p. 1221-1233, 2019.

CATHARIN, C. W. Álcool gel: um item indispensável para sair de casa? Gestão \& Tecnologia Faculdade Delta. v. 1, n. 30, p. 4-5, 2020.

CHEN, E.; FISCHBACK, M.; BELKAID, R. Skin microbiota-host interactions. Nature. v.24, n. 89, p. 427-436, 2018. 
DOMANSKY, C.R; BORGES, L.E. Manual para prevenção de lesões de pele. Recomendações baseadas em evidências. Rio de Janeiro: Editora Rubio,2012.

DRÉNO,B.; ARAVIISKAIA, E.; BERARDESCA, E.; GONTIJO,G.; SANCHEZ, M.; XIANG, L.; MARTIN,R.; BIEBER, T. Microbiome in healthy skin, update for dermatologists. Journal of the European Academy of Dermatology and Venerology: JEADV. vol 30, n. 12, 2016.

GAUER, D.; SILVIA, G. Análise qualitativa e quantitativa da microbiota das mãos dos funcionários de um posto de saúde. Revista Brasileira de Análises Clínicas. 2016

GONÇALVES,R. M. V; GORREIS,T. F; SORDI,R. M; SOUZA,E; RODRIGUES, N. H. Higiene das mãos em tempos de pandemia. Revista Eletrônica Acervo Enfermagem, v. 12, p. 7944, 2021.

GRICE, E.; SEGRE, J. The skin microbiome. Nature reviews. Microbiology. v. 9, n. 4, p. 244-253, 2011.

MINISTÉRIO DA SAÚDE; Protocolo de Manejo clínico da Covid-19 na atenção a saúde. vol.1, Brasília 2020.

NOGUEIRA, T. L. et al. Avaliação da prática da higienização das mãos em tempos de pandemia. Archives of Health, v. 2, n. 3, p. 422-429, 2021.

OLIVEIRA, E.D.; LEMOS, I.N. Ação viricida do álcool gel. Diversitas Journal. v. 6, n. 1, p. 757-768, 2021.

OLIVEIRA, P. K. Análise da composição bioquímica da pele por espectroscopia Raman. 2011. 79 f. Dissertação (Mestrado em Engenharia Biomédica)- Universidade do Vale do Paraíba, São José dos Campos, 2011.

QUEIROZ, J.P.N. O microbiota e o ser humano. Tese de Doutorado. Universidade de Coimbra. 2017.

ROCHA, L.A. Microbioma das mãos de enfermeiras, estudantes universitários e técnicos de laboratório associada à lavagem higiénica, 2007.

RODRIGUES, D.A., et al. Atlas de dermatologia em povos indígenas. São Paulo: Editora Unifesp. Doenças causadas por bactérias, p. 45-58, 2010.

SANFORD, J.; GALLO, R.. Functions of the skin microbiota in health and disease.

Seminars in immunology. vol. 25, n. 5, p. 370- 377, 2013.

SCHOMMER, N.; GALLO, R. Structure and function of the human skin microbiome.

Trends Microbiol. vol. 21, n. 12, p. 660-668, 2013.

SHIMOYA-BITTENCOURT, W. et al. Higienização simples e o uso do álcool $70 \%$ no controle de microrganismos das mãos em universitários da área da saúde. Fisioterapia Brasil, v. 20, n. 3, p. 376-383, 2019. 
SIVIERI, K., et al. Microbiota da pele: novos desafios. Arquivos Catarinenses de Medicina, v. 50, n. 1, p. 93-112, 2021.

TASSINARY, João. (2019). Raciocínio clínico aplicado á estética facial. Ed. Estética experts. 32-42 p.

TWO, A, et al. The Cutaneous Microbiome and Aspects of Skin Antimicrobial Defense System Resist Acute Treatment with Topical Skin Cleansers. Journal of investigative dermatology. v. 136, n. 10, p. 1950-1954, 2016.

WILSON, E.; NURINOVA, N.; ZAPKA, C.; FIERER, N.; WILSON, M. Review of human hand microbiome research. J Dermatol Sci.,2015.

Recebido em: 10/10/2021

Aprovado em: 12/11/2021

Publicado em: 17/11/2021 